Article

\title{
Decision and Performance Analysis of a Price-Setting Manufacturer with Options under a Flexible-Cap Emission Trading Scheme (ETS)
}

\author{
Shuyi Wang ${ }^{1,2}$, Zhenhua $\mathrm{Wu}^{1, *}$ and Baochen Yang ${ }^{1}$ \\ 1 College of Management and Economics, Tianjin University, Tianjin 300072, China; \\ wang0214@connect.hku.hk (S.W.); bchyang@tju.edu.cn (B.Y.) \\ 2 Department of Industrial and Manufacturing Systems Engineering, The University of Hong Kong, \\ Hong Kong, China \\ * Correspondence: zhenhuawu2017@gmail.com
}

Received: 3 September 2018; Accepted: 11 October 2018; Published: 14 October 2018

\begin{abstract}
An Emission Trading Scheme (ETS) is widely considered to reduce carbon emissions and achieve sustainability. Unsatisfactory results of European Union Emission trading scheme (EU ETS) make China's government propose a flexible-cap ETS system to overcome its weakness. This research is the first one introducing the flexible cap to limit the manufacturing carbon footprint. Current research on emission reduction primarily focuses on introducing option contracts to better develop the carbon market, with little consideration of the effectiveness of these contracts on the manufacturer's optimality facing demand risks. This research fills this research gap by using call option contract to reduce the emission costs for a price-setting manufacturer under the flexible ETS. Newsvendor models are built to investigate the behaviours and performances of manufacturers, with a call option contract when the price-driven demand is uncertain. The joint emission ordering and product pricing problem is solved by three emission ordering policies: the non-option, only option, and mixed emission ordering policy. Analytical and numerical studies have shown that the mixed policy outperforms the others in profitability, and the only option policy provides more flexibility but poor profitability. Furthermore, the mixed ordering policy better protects against price volatility and stringent emission restrictions. Managerial insights help emission-dependent manufacturers to manage their carbon assets for better survival in an increasingly stringent emission market. This paper investigates the effectiveness of the option contract on manufacture optimality in the flexible-cap ETS system, in which the joint emission ordering and production pricing problem under demand uncertainty is solved by the newsvendor model.
\end{abstract}

Keywords: decision analysis; option contracts; emission trading scheme (ETS); risk management; carbon asset management

\section{Introduction}

Carbon dioxide constitutes approximately $65 \%$ of total global greenhouse gas emissions and it is the principal cause of global warming. The 43rd Session of the Intergovernmental Panel on Climate Change (IPCC) set a goal of reducing carbon emissions by no less than $50 \%$ by 2050 , which implies that the economy must undergo serious challenges under this extremely stringent emission target $[1,2]$.

Due to low-carbon advocacy, many countries have developed and adopted pertinent low-carbon policies for the express purpose of reducing carbon dioxide in all industries, individually and collectively. Inevitably, the heavy-emission manufacturing industry is hampered by such emission restrictions. Surviving and thriving in this carbon-restricted environment remains problematic for these emission-concentrated firms; therefore, this topic deserves deep and thorough discussion. 
The emission trading scheme (ETS), following the "cap-and-trade" principle, is the first and remains the largest emission policy in the world. Under the ETS, a firm must hold a permit for each unit of carbon emission. Emission trading commences when emission shortages or leftovers occur.

Academic research has theoretically demonstrated the effectiveness of this approach for emission reduction [3]; however, the ETS has been less successful in practice. The results of the first and second phases of the EU ETS, for example, were disappointing. The erroneous estimates of emission allowance drop the EU ETS carbon price down to zero in 2007, and only $8 \%$ emission reduction was realized during the second phase (2008-2012) [4].

In addition to the undesirable practical application results, another disadvantage of such a fixed cap-and-trade mechanism is that it tends to stifle economic development because it neglects a firm's need to adjust capacities, particularly regarding expanding production to meet increased demands. In the short run, the mission-limited firms are highly likely to be limited to producing the cap-enabled quantity or suspending their production processes and benefiting from selling the assigned emission quotas.

Therefore, a flexible-cap ETS was introduced to relieve the low-carbon resistance through an emission/quantity ratio. Instead of endowing total fixed cap to choke production, a permitted unitary emission (PUE) level is built for each unit of products, which is below the average unitary emission level (AUE) of the industry. A firm's allowable emissions are proportional to PUE multiplied by the firm's total production. Emissions are regarded as a cost of production if unitary emission (UE) exceeds PUE, or otherwise as a byproduct if UE is below PUE. This cap realises the capacity growth in accordance with green restrictions. Empirical studies of the flexible-cap ETS remain scarce, even though China has proposed to leverage this emission ratio in practice to build a national carbon market.

The introduction of ETSs may greatly burden manufacturers with an emission allowance price. Under an ETS, the emission allowance appears to be a unique and irreplaceable raw material that dominates the production process. This allowance imposes additional financial stress on a firm's budget; otherwise, without sufficient tradable permits, production would be suspended. When a company can afford the extra cost per unit product, its yields are not subject to the emission cap. This behaviour aligns the emission reduction with capacity adjustments. Moreover, the flexible cap-and-trade policy shuts down inferior firms that cannot afford to install green improvements or added emission costs. These inferior firms have less competition but are highly polluted; thus, eliminating them is beneficial for the environment, with an insignificant impact on economic development. In the market, survival of the fittest is critical for the synergetic development of society and the environment.

Emission price volatility threatens the final consumer surplus that a manufacturer can achieve in the tradable permit market. This volatility was regarded as the primary ETS-related risk for industries by Chevallier, et al. [5]. Fortunately, the volatility can be effectively hedged by taking advantage of financial instruments, such as options.

Option contracts have been proven, as demonstrated through academic research and field practices, to strongly suppress economic, political, and financial uncertainty. Although the literature on option contracts is adequate, there have been no reports of the use of options to reduce the emission cost from the manufacturing perspective. This study is the first to consider a call option contract to hedge the financial risk of carbon emissions from an unpredictable demand. The call option is a right to purchase a certain amount of emission quota at a certain price before the expiration date, regardless of the emission price in the future. A premium is prepaid for the emission reservation. The manufacturer can decide whether to exercise the options at a pre-negotiated price when the demand uncertainty is resolved.

The effectiveness of the call option contract on a manufacturer's profitability and flexibility for meeting emission requirements was analysed using three emission ordering policies: non-option, only option, and mixed ordering policies. Under the non-option ordering policy, the manufacturer purchases the emission quota at the beginning of the production period. Profit losses may occur due to unsatisfied demand or spare emission quotas. The only option ordering policy is an extreme scenario 
in which a company can only purchase the option. Companies pay more for one unit of emissions, as the emission permit company charges the premium and an exercise price. The mixed ordering policy allows for manufacturers to simultaneously buy emission quotas and options. This policy lowers the possibility of the spare emission, and a higher emission cost is paid for satisfying the extra demand. This study investigates manufacturer performance and decision behaviours under each emission ordering policy and then seeks the best ordering pattern for better development in the carbon-limited environment.

Moreover, we assume that customers are rational and inclined to purchase the same product at a lower price. It is essential for the manufacturer to reasonably price its product. A trade-off exists between the price and demand, which helps manufacturers to earn maximum profits. This pricing problem is also solved in this study.

The newsvendor model is a classic model used in operations management and economic research. It enables the acquisition of capacity when encountering unknown demand by balancing the ordering quantity. In this study, three newsvendor models were built to analyse the emission ordering and product pricing problem, using a call option contract when the demand is price driven and unknown.

The objective of this research was to jointly determine the selling price and the emission ordering policy of a single product under a flexible-cap ETS to maximise the expected profit when a call option contract is available to hedge the demand risk.

The objective of this paper is to find out the best emission and the selling price strategy under the emission constraints. The contributions of our work can be summarized as follows:

1. It first adopts option contracts to balance emission reduction and production growth, given the demand uncertainty from the perspective of the manufacturing industry.

2. A flexible-cap ETS system is proposed, which has rarely been discussed in the existing literature, but it is recently deployed in China [6].

3. It compares the profitability and greenness of the emission-dependent manufacturer when the options are available and not available.

4. It jointly discusses the pricing and purchasing problems with the emission requirements, and it is of great importance for the manufacturer to thrive in the price-sensitive environment.

5. Newsvendor models are built considering the demand uncertainty, which is closer to the reality.

6. The resulted managerial insights guide the manufacturer to perform better and help the regulatory body to make more reasonable emission policies.

The remaining sections are arranged as follows. Related literature is reviewed in Section 2, and assumptions and notations are provided in Section 3. Three newsvendor models are provided in Section 4 to solve the product pricing and emission ordering problem using a call option contract. A numerical analysis is performed in Section 5 to further validate the mathematical results and the proposed model. In addition, conclusions and managerial insights are provided in Section 6. Furthermore, proofs are provided in Appendix A.

\section{Literature Review}

This study attempts to solve the option-enabled joint emission ordering and product pricing problem under the flexible-cap ETS at the manufacturer level. Therefore, three literature dimensions are presented: (1) ETS, (2) option contracts, and (3) joint pricing and ordering with a newsvendor model.

\subsection{Emission Trading Scheme}

The ETS, known as the cap-and-trade principle, has increased in popularity since the 1970s as a method of mitigating carbon emission through economic incentives [7]. The scheme's effectiveness and efficiency have been proven by scholars and practitioners. McAllister [8] defined the emission cap as the key factor in the low-carbon success of the ETS system. Current research on emission reduction focuses on a fixed cap due to the ease of implementation. However, this approach curbs economic 
development through the shrinkage in production of enterprises with insufficient emission quotas. Studies of the flexible-cap ETS remain scarce.

$\mathrm{Hu}$ and Zhou [9] designed a decision support system to optimise the production decisions with the emission reduction effort under a fixed-cap ETS system. Du, et al. [10] proposed a newsvendor model to analyse the impact of the cap-and-trade regulation in an emission-dependent supply chain. García-Alvarado, et al. [11] illustrated the adjustment of inventory strategies in an infinite-horizon remanufacturing system when introducing the cap-and-trade scheme. Sabzevar, et al. [12] employed a game theory Cournot model to analytically examine the profitable effect of fixed cap-and-trade regulation in the context of two firms with undesirable emissions. Xu, et al. [13] studied the production and pricing problem in a make-to-order (MTO) supply chain with a total free emission permit, and they [14] further discussed the manufacturer-retailer supply chain coordination problem under a fixed cap-and-trade system. Most related studies are based on a fixed-cap ETS system.

\subsection{Option Contracts}

Option contracts have been proven to effectively avoid risks and hedge uncertainty in finance. Extensive academic research and practical works have been inspired by the introduction and popularity of option contracts. In the operation research and optimisation problem field, Barnes-Schuster, et al. [15] investigated the effectiveness of option contracts on addressing market uncertainty. Gupta and Maranas [16] studied the benefits of the flexibility that is offered by emission option contracts in minimizing total emission abatement costs. Wang, et al. [17] adopted an option contract to coordinate a relief supply chain consisting of one supplier and one purchaser. Wan and Chen [18] found that option contracts benefit the retailer during inflation when solving the multi-period replenishment problem. Wang and Chen [19] used a call option contract to solve the joint ordering and pricing problem with the newsvendor models in the new industry. Based on this research, Wang and Chen [20] further studied the ability of the call option contract on the new supply chain coordination problem; the optimal option pricing policy was obtained in that work.

In 2006, the European Climate Exchange (ECX) introduced the option instruments to hedge the risk in the European Union Emissions Trading Scheme (EU ETS) [21]. Uhrig-Homburg and Wagner [21] noted that EU ETSs are being developed similarly to other financial and commodity markets, and that such ETSs provide an opportunity for long-term success, with the help of futures and options. Chevallier, et al. [22] provided the first tentative assessment of investors' risk behaviours under the ETS, with futures and call options in a case study. Chesney and Taschini [23] addressed the emission option pricing problem through dynamic optimisation under asymmetric information.

Previous empirical literature has primarily focused on the influences of the introduction of an option contract on the performance of the ETS, such as the study by Chevallier, Le Pen and Sévi [5], with minimal consideration of the player's benefits that are achievable through option contracts under the emission restrictions. The present study fills this gap by incorporating a call option contract to jointly determine the emission ordering and product pricing decisions under the ETS system.

\subsection{Joint Ordering and Pricing with the Newsvendor Model}

The joint ordering and pricing problem has received much attention in academic works and field practice. Considering the demand uncertainty, the newsvendor model, which is widely used in operation management and economic research, provides results. Studies that have closely examined the joint ordering and pricing problem with the newsvendor model are described, as follows.

Petruzzi and Dada [24] solved a newsvendor problem in which the selling price and the order quantity of the product are simultaneously set considering random demand. Agrawal and Seshadri [25] considered a risk-averse retailer under uncertain demand; a joint selling price and order quantity problem was built with the objective of maximising profit. Yao, et al. [26] studied the joint ordering and pricing problem in the newsvendor model and examined the influence of operational problems on decision making at the firm level. Wang and Webster [27] modelled a loss-averse firm's 
decision making, in terms of pricing and order quantity, in a single-period newsvendor problem and examined the risk neutrality. Abad [28] determined the selling price and optimal order size for a price-setting newsvendor when the demand follows a stochastic function of the selling price. In addition to the demand uncertainty, Tang, et al. [29] considered the yield uncertainty and built newsvendor models to develop optimal pricing and ordering decisions to maximise the expected profit. Jadidi, et al. [30] built a single-period newsvendor model, in which the buyer decides the optimal pricing and inventory decisions when encountering a dominate supplier that offers an all-unit quantity discount. $\mathrm{Hu}$ and $\mathrm{Su}$ [31] explored the best purchasing and selling decisions in the newsvendor frame, in which alternative suppliers with different price fluctuation processes are available for creating a time-flexible order.

Although the joint pricing and ordering problem combined with the newsvendor has been well discussed, this study first incorporated the option contracts to help the manufacturer determine its optimal emission order quantity and product selling price using the newsvendor model under a flexible-cap ETS system. Moreover, the introduction of the flexible emission cap narrows the research gap and it provides more choices and patterns for the enterprise's carbon asset management.

\section{Problem Formulation}

This section defines the product pricing and emission ordering problem, and related notations and assumptions are provided.

\subsection{Basic Model Description}

This research considered an emission-dependent manufacturer that jointly determines the selling price and the emission quantity to capture the optimal expected profit, in which the demand is price-driven and uncertain. A flexible-cap ETS system is used, in which the emission quota needed is proportional to the production yield. Batch production is scheduled after receiving a sufficient emission quota. Random demand makes it a challenge to determine the emission quantity, and emission price volatility further harms a firm's final profit. Therefore, a call option contract was proposed to address the demand uncertainty and the emission price fluctuation. If the customers regard the selling price as the primary consideration, then price discovery is crucial for the manufacturer to balance the demand and emission cost.

At the beginning of the selling season, the manufacturer purchases emission quotas and/or emission options from the emission permit supplier based on the preliminary demand forecast. After receiving the quotas, the manufacturer schedules production and receives orders from its customers during the selling season. If it receives more orders than its yield, the manufacturer can choose to reject the orders or to exercise the emission options to produce more. Rejecting orders means losing demand and brand, and the associated costs include the goodwill price. The spare emission quota can be resold at the end of the selling period at a resale price.

This model is limited in a two-stage supply chain, and only two members are considered in this research. It is suitable for the manufacturing industries, and the following numerical study focuses on China's chemical industry, which burdens massive energy use and emission generation.

\subsection{Notations and Assumptions}

The parameters and decision variables used in this research are presented in Tables 1 and 2 , respectively. 
Table 1. Notations for parameters.

\begin{tabular}{|c|c|}
\hline Demand Function & Description \\
\hline$D(p, \varepsilon)$ & $\begin{array}{l}\text { The stochastic price-driven demand function for the single product, which is } \\
\text { continuous and differentiable. } D(p, \varepsilon)=y(p)+\varepsilon \text {. }\end{array}$ \\
\hline$y(p)$ & $\begin{array}{l}\text { The decreasing and deterministic demand function for selling price. } \\
y(p)=a-b p\end{array}$ \\
\hline$a$ & The market scale for the single product. $a>0$ \\
\hline$b$ & The price sensitivity to the demand. $b>0$. \\
\hline$\varepsilon$ & $\begin{array}{l}\text { The random variable for the demand uncertainty. } \\
\varepsilon \in[A, B], E(\varepsilon)=u . A>-a \text {. }\end{array}$ \\
\hline$f(\cdot)$ & The probability density function for $\varepsilon$. \\
\hline$F(\cdot)$ & The non-negative, invertible distribution function for $\varepsilon$. \\
\hline Parameters & Description \\
\hline$e$ & The emission level of the product \\
\hline$k$ & The emission cap level of the product \\
\hline$c$ & The average total cost, including production, inventory, and managerial cost, etc. \\
\hline$s$ & The resale price of the spare emission credits. \\
\hline$g$ & $\begin{array}{l}\text { The unit goodwill cost for the unsatisfied demand, e.g., losing brand and } \\
\text { unsatisfied orders. }\end{array}$ \\
\hline$w_{0}$ & The option price of the emission credits. \\
\hline$w_{b}$ & The order price of the emission credits. \\
\hline$w_{e}$ & The exercising price of the emission credits. \\
\hline \multirow[t]{2}{*}{$x^{+}$} & The larger value comparing zero with $x, x^{+}=\max (0, x)$. \\
\hline & $p>c+w_{o}+w_{e}>c+w_{b}, w_{o}+w_{e}>w_{b}>w_{o}+s, w_{e}>s$ \\
\hline
\end{tabular}

Table 2. Notations for decision variables.

\begin{tabular}{cl}
\hline Decision Variables & \multicolumn{1}{c}{ Description } \\
\hline$p$ & The unit selling price of the single product. \\
\hline$q$ & The total emission quantity for the product \\
\hline$q_{0}$ & The emission option quantity for the product \\
\hline$q_{b}$ & The emission order quantity for the product \\
\hline$r$ & $\begin{array}{l}\text { The stocking factor for the non-option model, } r^{n}=\frac{q}{e-k}-y(p), q=q_{b} \\
\text { The stocking factor for the only-option model, } r^{o}=\frac{q}{e-k}-y(p), q=q_{o} \\
\text { The stocking factor for the mixed model, } r^{m}=\frac{q}{e-k}-y(p), q=q_{o}+q_{b}\end{array}$ \\
\hline
\end{tabular}

The following specific assumptions are adopted for the development of the proposed newsvendor models.

Assumption 1: The manufacturer has no capacity limit expected for emission quotas.

Assumption 2: The demand is positive, and the profit is non-negative.

$$
p>c+w_{o}+w_{e}>c+w_{b}
$$

The manufacturer will have negative profit. This assumption ensures the survival of the manufacturer.

Assumption 3: The additive demand function is used to build the price-driven demand with uncertainty. $D(p, \varepsilon)=y(p)+\varepsilon, y(p)=a-b p(a>0, b>0), \varepsilon \in[A, B], A>-a, E(\varepsilon)=\mu$.

Mills [32] first defined the additive demand function as $D(p, \varepsilon)=y(p)+\varepsilon$. Thereafter, Petruzzi and Dada [24] and Qi, et al. [33] extended the function through the relationships $y(p)=a-b p(a>0, b>0)$ and $D(p, \varepsilon)=y(p)+\varepsilon$, where $a$ is the market scale and $b$ is a coefficient of price sensitivity. This extended additive demand function is considered in this study, and it follows 
the uniform distribution with $\varepsilon \in[A, B]$, and $E(\varepsilon)=\mu$. The constraint $A>-a$ is reasonable to ensure positive demand.

Assumption 4: The flexible cap is proportional to the production yield.

Under the flexible-cap ETS principle, the government caps the unit emission level of the product but not the emission amount of the total production. The total emission cap is expressed through the relationship $K=k q$, where the emission cap level $k$ is smaller than the average emission level $e$ of an industry. The needed emission permits $(e-k) q$ increase proportionally with the yield rise.

Assumption 5: The spare emission can be resold at a lower price than the exercise price of the option: $w_{e}>s$.

This assumption prevents the manufacturer from exercising all options for the resale benefits, including when no actual demand exists.

Assumption 6: The manufacturer is assumed to make orders and purchase options from the emission permit supplier, and $w_{o}+w_{e}>w_{b}>w_{o}+s$.

The manufacturer and the emission permit supplier have incentives to conduct the call option contract by $w_{o}+w_{e}>w_{b}>w_{o}+s$. The manufacturer hedges risks from uncertain demand, while the emission permit supplier obtains a higher price through the options.

Assumption 7: The demand distribution has a non-decreasing failure rate (NDFR), as $(\cdot)=f(\cdot) / \bar{F}(\cdot)$, and ${ }^{\prime}(\cdot) \geq 0$.

The NDFR is widely used to formulate the demand distributions, such as the normal, the power, the extreme value, and the negative exponential [10].

\section{Newsvendor Models for Three Emission Ordering Policies}

This section mathematically explores the decision behaviours and profit performance of a manufacturer under three emission ordering policies while using newsvendor models.

\subsection{Non-Option Emission-Ordering Policy Scenario}

Under the non-option emission-ordering assumption, the manufacturer purchases emission quotas only from the emission permit supplier. No options are allowed under this assumption, and this non-option scenario is a useful benchmark, as it reflects the basic emission ordering policy that was adopted by most manufacturers in the carbon market. Ordering sufficient emission quotas is crucial to assure production, and the spare emission permits are resold at the resale price $s$ after the selling season. The manufacturer orders emission quotas $q^{n}$ for producing $\frac{q^{n}}{e-k}$ product units and then sells these quotas to the retailer at the selling price $p^{n}$. The total emission quantity is equivalent to the emission order quantity, that is, $q^{n}=q_{b}^{n}$. The newsvendor model that was built for this scenario is denoted as the non-option model for simplicity, and the expected profit function of the non-option model is shown as

$$
\prod\left(q^{n}, p^{n}\right)=\left(p^{n}-c\right) \cdot \min \left[D, \frac{q^{n}}{e-k}\right]+s \cdot\left[q^{n}-(e-k) \cdot D\right]^{+}-w_{b} \cdot q^{n}-g \cdot\left[D-\frac{q^{n}}{e-k}\right]^{+}
$$

To solve this problem, a stocking factor $r$, also called riskless leftovers, is adopted based on the research works of Petruzzi and Dada [24] and Chen, et al. [34] and Wang and Chen [19]. This factor is defined as $r^{n}=\frac{q^{n}}{e-k}-y\left(p^{n}\right)$ in this scenario. The leftover occurs when $r^{n}>\varepsilon$, and the shortage occurs when $r^{n}<\varepsilon$. The optimal total emission quantity decision is $q^{n *}=(e-k) \cdot\left(y\left(p^{n *}\right)+r^{n *}\right)$, with the 
optimal selling price $p^{n *}$. By substituting $D\left(p^{n}, \varepsilon\right)=y\left(p^{n}\right)+\varepsilon$ and $r^{n}$, the expected profit function can be written as

$$
\begin{aligned}
\Pi\left(r^{n}, p^{n}\right)= & \left(p^{n}-c\right) \cdot \min \left[y\left(p^{n}\right)+\varepsilon, y\left(p^{n}\right)+r^{n}\right]+s \cdot(e-k) \cdot\left[r^{n}-\varepsilon\right]^{+} \\
& -w_{b} \cdot(e-k) \cdot\left[y\left(p^{n}\right)+r^{n}\right]-g \cdot\left[\varepsilon-r^{n}\right]^{+}
\end{aligned}
$$

Define $\Lambda\left(r^{n}\right)=\int_{A}^{r^{n}}\left(r^{n}-x\right) f(x) d x$ for the expected leftovers of the product when setting a large emission order, and $\Gamma\left(r^{n}\right)=\int_{r^{n}}^{B}\left(x-r^{n}\right) f(x) d x$ for the expected shortage of the product when setting a small emission order. We can obtain the expected profit, denoted $E\left[\Pi\left(r^{n}, p^{n}\right)\right]$, as follows:

$$
\begin{aligned}
E\left[\Pi\left(r^{n}, p^{n}\right)\right] & =\left[p^{n}-c-w_{b} \cdot(e-k)\right] \cdot\left[y\left(p^{n}\right)+\mu\right]-\left(w_{b}-s\right) \cdot(e-k) \cdot \Lambda\left(r^{n}\right) \\
& -\left[p^{n}-c+g-w_{b} \cdot(e-k)\right] \cdot \Gamma\left(r^{n}\right)
\end{aligned}
$$

For ease of presentation, the equation can be stated as

$$
E\left[\prod\left(r^{n}, p^{n}\right)\right]=\psi\left(p^{n}\right)-\chi\left(r^{n}, p^{n}\right)
$$

where

$$
\begin{gathered}
\psi\left(p^{n}\right)=\left[p^{n}-c-w_{b} \cdot(e-k)\right] \cdot\left[y\left(p^{n}\right)+\mu\right] \\
\chi\left(r^{n}, p^{n}\right)=\left(w_{b}-s\right) \cdot(e-k) \cdot \Lambda\left(r^{n}\right)+\left[p^{n}-c+g-w_{b} \cdot(e-k)\right] \cdot \Gamma\left(r^{n}\right)
\end{gathered}
$$

$\psi\left(p^{n}\right)$ represents the riskless profit without consideration of demand uncertainty, which is considered in the loss function as $\chi\left(r^{n}, p^{n}\right) .\left(w_{b}-s\right) \cdot(e-k) \cdot \Lambda\left(r^{n}\right)$ is the overage cost for the spare emission permits and $\left[p^{n}-c+g-w_{b} \cdot(e-k)\right] \cdot \Gamma\left(r^{n}\right)$ describes the shortage cost for decreasing demand.

Lemma 1. In the non-option emission ordering scenario, there exists an optimal selling price of the product with a given $r^{n}$ as $p^{n *} \equiv p\left(r^{n}\right)=\bar{p}^{n} \frac{\Gamma\left(r^{n}\right)}{2 b}$, where $\bar{p}^{n}=\frac{a+\left[c+w_{b} \cdot(e-k)\right] \cdot b+u}{2 b}$.

When the stocking factor $r^{n}$ is given, the expected profit function is concave due to $\frac{\partial^{2} E\left[\Pi\left(r^{n}, p^{n}\right)\right]}{\partial p^{n 2}}<0$. Thus, the optimal selling price of the product can be obtained by solving $\frac{\partial E\left[\Pi\left(r^{n}, p^{n}\right)\right]}{\partial p^{n}}=0$.

$\bar{p}^{n}$ denotes the optimal riskless selling price of the product and $\frac{\Gamma\left(r^{n}\right)}{2 b}$ refers to the price loss from demand uncertainty.

Lemma 2. In the non-option emission ordering scenario, the optimal ordering decisions with a given $p^{n}$ exists. Additionally, the optimal total emission quantity is uniquely determined by a function of $p^{n}$, as $q^{n *} \equiv q\left(p^{n}\right)=(e-k) \cdot\left(y\left(p^{n}\right)+r^{n *}\right)$.

When the unit selling price $p^{n}$ is given, the expected profit function is concave due to $\frac{\partial^{2} E\left[\Pi\left(r^{n}, p^{n}\right)\right]}{\partial r^{n 2}}<0$. Thus, the optimal stocking factor $r^{n *}$ can be obtained by solving $\frac{\partial E\left[\Pi\left(r^{n}, p^{n}\right)\right]}{\partial r^{n}}=0$. Clearly, the optimal total emission quantity is $q^{n *}=(e-k) \cdot\left(y\left(p^{n *}\right)+r^{n *}\right)$, with the optimal stocking factor $r^{n *}$.

Proposition 1. Under the non-option emission ordering policy, if $2 b \cdot\left[p^{n}-c+g-s \cdot(e-k)\right] \cdot f(A)>1$, then the joint optimal product pricing and emission ordering decisions are uniquely determined by functions of the stocking factor $r^{n *}$, which satisfies $\left[\bar{p}^{n}-\frac{\Gamma\left(r^{n}\right)}{2 b}-c+g-s \cdot(e-k)\right] \cdot\left[1-F\left(r^{n}\right)\right]=\left(w_{b}-s\right) \cdot(e-k)$. Additionally, the optimal total emission quantity and selling price are $q^{n *} \equiv q\left(p^{n *}\right)=(e-k) \cdot\left(y\left(p^{n *}\right)+r^{n *}\right)$ and $p^{n *} \equiv p\left(r^{n *}\right)=\bar{p}^{n *}-\frac{\Gamma\left(r^{n *}\right)}{2 b}$, respectively.

Proof. Please see the Appendix A. 


\subsection{Only-Option Emission Ordering Policy Scenario}

The only option emission ordering policy assumes that the manufacturer cedes the emission order manner and purchases the emission options solely to fill the uncertain demand. This approach reduces the demand risk at the expense of the higher unit emission cost, due to $w_{o}+w_{e}>w_{b}$. The manufacturer exercises the emission options $q_{o}^{o}$ to meet the retailers' demand and receives $p^{o}$ for each sold product. The spare options have no value to resell, and a shortage occurs, due to a low option order. The total emission quantity is equivalent to the emission option quantity, that is, $q^{o}=q_{0}^{o}$. The newsvendor that was built for this scenario is denoted as the only option model for simplicity, and the expected profit function of the only option model is shown as

$$
\prod\left(q_{o}^{o}, p^{o}\right)=\left(p^{o}-c\right) \cdot \min \left[D, \frac{q_{o}^{o}}{e-k}\right]-w_{o} \cdot q_{o}^{o}-w_{e} \cdot \min \left[(e-k) \cdot D, q_{o}^{o}\right]-g \cdot\left[D-\frac{q_{o}^{o}}{e-k}\right]^{+}
$$

The stocking factor of the only option model is similarly defined as $r^{o}=\frac{q_{0}^{o}}{e-k}-y\left(p^{o}\right)$. The optimal total emission quantity decision is $q^{o *}=(e-k) \cdot\left(y\left(p^{o *}\right)+r^{o *}\right)$, with the optimal selling price $p^{o *}$. By substituting $D\left(p^{o}, \varepsilon\right) y\left(p^{o}\right)+\varepsilon$ and $r^{o}$, the expected profit function can be written as

$$
\begin{aligned}
\Pi\left(r^{o}, p\right)= & {\left[p^{o}-c-w_{e} \cdot(e-k)\right] \cdot \min \left[y\left(p^{o}\right)+\varepsilon, y\left(p^{o}\right)+r^{o}\right]-w_{o} \cdot(e-k) \cdot\left[y\left(p^{o}\right)+r^{o}\right] } \\
& -g \cdot\left[\varepsilon-r^{o}\right]^{+}
\end{aligned}
$$

Defining $\Lambda\left(r^{o}\right)=\int_{A}^{r^{o}}\left(r^{o}-x\right) f(x) d x$ for the expected option leftovers when $r^{o}>\varepsilon$, and $\Gamma\left(r^{o}\right)=$ $\int_{r^{o}}^{B}\left(x-r^{o}\right) f(x) d x$ for the expected option shortage when $r^{o}<\varepsilon$, we can obtain the expected profit, denoted $E\left[\Pi\left(r^{o}, p^{o}\right)\right]$, as follows:

$$
\begin{aligned}
\Pi\left(r^{o}, p^{o}\right)= & {\left[p^{o}-c-\left(w_{o}+w_{e}\right) \cdot(e-k)\right] \cdot\left[y\left(p^{o}\right)+\mu\right]-w_{o} \cdot(e-k) \cdot \Lambda\left(r^{o}\right) } \\
& -\left[p^{o}-c+g-\left(w_{o}+w_{e}\right) \cdot(e-k)\right] \cdot \Gamma\left(r^{o}\right)
\end{aligned}
$$

For ease in presentation, the equation can be rewritten as

$$
E\left[\prod\left(r^{o}, p^{o}\right)\right]=\psi\left(p^{o}\right)-\chi\left(r^{o}, p^{o}\right)
$$

where

$$
\begin{gathered}
\psi\left(p^{o}\right)=\left[p^{o}-c-\left(w_{o}+w_{e}\right) \cdot(e-k)\right] \cdot\left[y\left(p^{o}\right)+\mu\right] \\
\chi\left(r^{o}, p^{o}\right)=w_{o} \cdot(e-k) \cdot \Lambda\left(r^{o}\right)+\left[p^{o}-c+g-\left(w_{o}+w_{e}\right) \cdot(e-k)\right] \cdot \Gamma\left(r^{o}\right)
\end{gathered}
$$

$\psi\left(p^{o}\right)$ demonstrates the riskless profit without demand uncertainty and $\chi\left(r^{o}, p^{o}\right)$ formulates the uncertainty cost that lowers the expected profit. $w_{0} \cdot(e-k) \cdot \Lambda\left(r^{0}\right)$ is the leftover cost for the spare emission options, and $\left[p^{o}-c+g-\left(w_{o}+w_{e}\right) \cdot(e-k)\right] \cdot \Gamma\left(r^{o}\right)$ describes the shortage cost for unfilled demand.

Lemma 3. In the only option emission ordering scenario, there exists an optimal selling price of the product with a given stocking factor $r^{o}$, as $p^{o *} \equiv p\left(r^{o}\right)=\bar{p}^{o}-\frac{\Gamma\left(r^{o}\right)}{2 b}$, where $\bar{p}^{o}=\frac{a+\left[c+\left(w_{o}+w_{e}\right) \cdot(e-k)\right] \cdot b+u}{2 b}$.

When the stocking factor $r^{o}$ is given, the expected profit function is concave due to $\frac{\partial^{2} E\left[\Pi\left(r^{o}, p^{o}\right)\right]}{\partial p^{02}}<0$. Thus, the optimal selling price of the product can be obtained by solving $\frac{\partial E\left[\Pi\left(r^{0}, p^{o}\right)\right]}{\partial p^{o}}=0$.

$\bar{p}^{o}$ denotes the optimal riskless selling price of the product and $\frac{\Gamma\left(r^{\circ}\right)}{2 b}$ refers to the price loss from demand uncertainty. 
Lemma 4. In the only option emission ordering scenario, the optimal ordering decisions exist for a given $p^{0}$. Additionally, the optimal total emission quantity is uniquely determined by a function of $p^{o}$, as $q^{o *} \equiv q\left(p^{o}\right)=$ $(e-k) \cdot\left(y\left(p^{o}\right)+r^{o *}\right)$.

When the unit selling price $p^{0}$ is given, the expected profit function is concave, due to $\frac{\partial^{2} E\left[\Pi\left(r^{o}, p^{o}\right)\right]}{\partial r^{02}}<0$. Thus, the optimal stocking factor $r^{o *}$ can be obtained by solving $\frac{\partial E\left[\Pi\left(r^{o}, p^{o}\right)\right]}{\partial r^{0}}=0$. Clearly, the optimal total emission quantity is $q^{o *}=(e-k) \cdot\left(y\left(p^{o *}\right)+r^{o *}\right)$, with the optimal stocking factor $r^{o *}$.

Proposition 2. Under the only option emission ordering policy, if $2 b \cdot\left[p^{o}-c+g-w_{e} \cdot(e-k)\right] \cdot f(A)>1$, the joint optimal product pricing and emission ordering decisions are uniquely determined by the functions of the stocking factor $r^{m *}$, which satisfy $\left[\bar{p}^{o}-\frac{\Gamma\left(r^{0}\right)}{2 b}-c+g-w_{e} \cdot(e-k)\right] \cdot\left[1-F\left(r^{o}\right)\right]=w_{o} \cdot(e-k)$. Additionally, the optimal total emission quantity and selling price are $q^{o *} \equiv q\left(p^{o *}\right)=(e-k) \cdot\left(y\left(p^{o *}\right)+r^{o *}\right)$ and $p^{o *} \equiv p\left(r^{o *}\right)=\bar{p}^{o *}-\frac{\Gamma\left(r^{0 *}\right)}{2 b}$, respectively.

Proof. Please see the Appendix A.

\subsection{Mixed Emission Ordering Policy Scenario}

In the mixed emission ordering scenario, the manufacturer is able to buy emission quotas and to purchase options before receiving the orders from the retailer. The batch production is scheduled based on the emission quotas received. If the production is insufficient, the manufacturer can exercise the options to produce more. Three decision variables are considered: the emission order quantity $q_{b}^{m}$, the emission option quantity $q_{o}^{m}$, and the unit selling price of the product $p^{m}$. The total emission quantity that can be put into the production process is $q^{m}=q_{o}^{m}+q_{b}^{m}$, such that determining the values of $\left(q_{o}^{m}, q_{b}^{m}, p^{m}\right)$ is equivalent to determine the values of $\left(q_{o}^{m}, q^{m}, p^{m}\right)$. The newsvendor that was built for this scenario is termed the mixed model for simplicity, and the expected profit function of the mixed model is shown as

$$
\begin{aligned}
\Pi\left(q_{o}^{m}, q^{m}, p^{m}\right)= & \left(p^{m}-c\right) \cdot \min \left[D, \frac{q^{m}}{e-k}\right]+s \cdot\left[q^{m}-q_{o}^{m}-(e-k) \cdot D\right]^{+}-w_{b} \cdot\left(q^{m}-q_{o}^{m}\right) \\
& -w_{o} \cdot q_{o}^{m}-w_{e} \cdot\left[\min \left[(e-k) \cdot D-\left(q^{m}-q_{o}^{m}\right), q_{o}^{m}\right]\right]^{+}-g \cdot\left[D-\frac{q^{m}}{e-k}\right]^{+}
\end{aligned}
$$

Similarly, the stocking factor is defined as $r^{m}=\frac{q^{m}}{e-k}-y\left(p^{m}\right)$ in this scenario. It is clear that the optimal total emission quantity is $q^{m *}=(e-k) \cdot\left(y\left(p^{m *}\right)+r^{m *}\right)$, with the optimal selling price $p^{m *}$. By substituting $D\left(p^{m}, \varepsilon\right)=y\left(p^{m}\right)+\varepsilon$ and $r^{m}$, the expected profit function can be written as

$$
\begin{aligned}
\Pi\left(q_{o}^{m}, r^{m}, p^{m}\right)= & \left(p^{m}-c\right) \cdot \min \left[y\left(p^{m}\right)+\varepsilon, y\left(p^{m}\right)+r^{m}\right]+s \cdot(e-k) \cdot\left[r^{m}-\frac{q_{o}^{m}}{e-k}-\varepsilon\right]^{+} \\
& -w_{o} \cdot q_{o}^{m}-w_{b} \cdot(e-k) \cdot\left(y\left(p^{m}\right)+r^{m}-\frac{q_{o}^{m}}{e-k}\right) \\
& -w_{e} \cdot(e-k) \cdot\left[\min \left[\left(\varepsilon-r^{m}+\frac{q_{o}^{m}}{e-k}\right), \frac{q_{o}^{m}}{e-k}\right]\right]^{+}-g \cdot\left[\varepsilon-r^{m}\right]^{+}
\end{aligned}
$$

Let $\hat{q}_{o}^{m}=\frac{q_{o}^{m}}{e-k}$, where $\hat{q}_{o}^{m}$ refers to the option-enabled production quantity. Then, we can obtain

$$
\begin{aligned}
\Pi\left(\hat{q}_{o}^{m}, r^{m}, p^{m}\right)= & \left(p^{m}-c\right) \cdot \min \left[y\left(p^{m}\right)+\varepsilon, y\left(p^{m}\right)+r^{m}\right]+s \cdot(e-k) \cdot\left[r-\hat{q}_{o}^{m}-\varepsilon\right]^{+} \\
& -w_{o} \cdot(e-k) \cdot \hat{q}_{o}^{m}-w_{b} \cdot(e-k) \cdot\left(y\left(p^{m}\right)+r^{m}-\hat{q}_{o}^{m}\right) \\
& -w_{e} \cdot(e-k) \cdot\left[\min \left[\left(\varepsilon-r^{m}+\hat{q}_{o}^{m}\right), \hat{q}_{o}^{m}\right]\right]^{+}-g \cdot\left[\varepsilon-r^{m}\right]^{+}
\end{aligned}
$$

Define $\Lambda\left(\hat{q}_{o}^{m}, r^{m}\right)=\int_{A}^{r^{m}-\hat{q}_{o}^{m}}\left(r-\hat{q}_{o}^{m}-x\right) f(x) d x$ for the expected leftovers of the order-enabled product, when $r^{m}$ is chosen to be excessively high, $\Omega\left(\hat{q}_{o}^{m}, r\right)=\int_{r^{m}}^{r^{m}}-\hat{q}_{0}^{m}\left(r^{m}-x\right) f(x) d x$ for expected leftovers of the option-enabled product when $\hat{q}_{o}^{m}$ is excessively high, and $\Gamma\left(r^{m}\right)=\int_{r^{m}}^{B}\left(x-r^{m}\right) f(x) d x$ 
for the excepted shortage of the product when $r^{m}$ is excessively low. We can obtain the expected profit, denoted $E\left[\Pi\left(\hat{q}_{o}^{m}, r^{m}, p^{m}\right)\right]$, as follows:

$$
\begin{aligned}
E\left[\Pi\left(\hat{q}_{o}^{m}, r^{m}, p^{m}\right)\right] & =\left[p^{m}-c-w_{b} \cdot(e-k)\right] \cdot\left[y\left(p^{m}\right)+\mu\right]-\left[p^{m}-c+g-w_{b} \cdot(e-k)\right] \cdot \Gamma\left(r^{m}\right) \\
& -\left(w_{b}-s\right) \cdot(e-k) \cdot \Lambda\left(\hat{q}_{o}^{m}, r^{m}\right)-\left(w_{b}-w_{e}\right) \cdot(e-k) \cdot \Omega\left(\hat{q}_{o}^{m}, r^{m}\right) \\
& -w_{o} \cdot(e-k) \cdot \hat{q}_{o}^{m} \cdot \int_{A}^{r^{m}} \hat{q}_{o}^{m} f(x) d x-\left(w_{o}-w_{b}+w_{e}\right) \cdot(e-k) \cdot \hat{q}_{o}^{m} \cdot \int_{r^{m}-\hat{q}_{o}^{m}}^{B} f(x) d x
\end{aligned}
$$

For ease of presentation, the equation can be stated as

$$
E\left[\prod\left(\hat{q}_{o}^{m}, r^{m}, p^{m}\right)\right]=\psi\left(p^{m}\right)-\chi\left(\hat{q}_{o}^{m}, r^{m}, p^{m}\right)
$$

where

$$
\begin{aligned}
\psi\left(p^{m}\right)=\left[p^{m}-c-w_{b} \cdot(e-k)\right] \cdot\left[y\left(p^{m}\right)+\mu\right] \\
\chi\left(\hat{q}_{o}^{m}, r^{m}, p^{m}\right)=w_{o} \cdot(e-k) \cdot \hat{q}_{o}^{m} \cdot \int_{A}^{r^{m}-\hat{q}_{o}^{m}} f(x) d x+\left(w_{o}-w_{b}+w_{e}\right) \cdot(e-k) \cdot \hat{q}_{o}^{m} \cdot \int_{r^{m}-\hat{q}_{o}^{m}}^{B} f(x) d x \\
+\left(w_{b}-s\right) \cdot(e-k) \cdot \Lambda\left(\hat{q}_{o}^{m}, r^{m}\right)+\left(w_{b}-w_{e}\right) \cdot(e-k) \cdot \Omega\left(\hat{q}_{o}^{m}, r^{m}\right) \\
+\left[p^{m}-c+g-w_{b} \cdot(e-k)\right] \cdot \Gamma\left(r^{m}\right)
\end{aligned}
$$

where $\psi\left(p^{m}\right)$ represents the riskless profit that a manufacturer can obtain by ignoring the demand uncertainty for a given price. Additionally, $\chi\left(\hat{q}_{o}^{m}, r^{m}, p^{m}\right)$ is the loss function that results from the demand fluctuation. $w_{0} \cdot(e-k) \cdot \hat{q}_{0}^{m} \cdot \int_{A}^{r^{m}} \hat{q}_{0}^{m} f(x) d x$ is the option cost for the probability that all options are spare. When spare options exist, some loss of profits originates from the option-purchasing cost for the remaining emission options. $\left(w_{o}-w_{b}+w_{e}\right) \cdot(e-k) \cdot \hat{q}_{o}^{m} \cdot \int_{r^{m}}^{B}-\hat{q}_{0}^{m} f(x) d x$ refers to the profit loss for exercising the options due to $w_{o}+w_{e}>w_{b}$, and this term originates from the insufficient emission quantity order. The manufacturer needs to pay $\left(w_{b}-s\right)$ to set a large emission order and to pay $\left[p^{m}-c+g-w_{b} \cdot(e-k)\right]$ for the shortage of emission permits. The riskless function $\psi\left(p^{m}\right)$ formulates the unit profit by $\left[p^{m}-c-w_{b} \cdot(e-k)\right]$; however, the incremental value is $\left[p^{m}-c-\left(w_{0}+w_{e}\right) w_{0} \cdot(e-k)\right]$ for each option. Thus, the loss function lessens the extra profit by $\left(w_{b}-w_{e}\right) \cdot(e-k) \cdot \Omega\left(\hat{q}_{o}^{m}, r^{m}\right)$. The expected profit that a manufacturer can achieve is shown in Equation (18); the riskless profit less the profit loss from the demand uncertainty.

Lemma 5. In the mixed emission ordering policy scenario, there exists an optimal selling price of the product for given values of $\left(\hat{q}_{o}^{m}, r^{m}\right)$. The price is uniquely determined by a function of $r^{m}$, as $p^{m *} \equiv p\left(r^{m}\right)=\bar{p}^{m}-\frac{\Gamma\left(r^{m}\right)}{2 b}$, where $\bar{p}^{m}=\frac{a+\left[c+w_{b} \cdot(e-k)\right] \cdot b+u}{2 b}$.

When the values of $\left(\hat{q}_{0}^{m}, r^{m}\right)$ are given, the expected profit function is concave due to $\frac{\partial^{2} E\left[\Pi\left(\hat{q}_{0}^{m}, r^{m}, p^{m}\right)\right]}{\partial p^{m 2}}<0$. Thus, the optimal selling price of the product can be obtained by solving $\frac{\partial E\left[\Pi\left(\hat{q}_{o}^{m}, r^{m}, p^{m}\right)\right]}{\partial p^{m}}=0$.

$\bar{p}^{m}$ denotes the optimal riskless selling price of the product, and $\frac{\Gamma\left(r^{m}\right)}{2 b}$ refers to the price loss from the demand uncertainty.

Lemma 6. In the mixed emission ordering policy scenario, there exist optimal ordering decisions for a given $p^{m}$. Additionally, the optimal total emission quantity is uniquely determined by a function of $p$, as $q^{m *} \equiv q\left(p^{m}\right)=$ $(e-k) \cdot\left(y\left(p^{m}\right)+r^{m *}\right)$.

Proof. Please see the Appendix A.

Proposition 3. Under the mixed emission ordering policy, if $2 b \cdot\left[p^{m}-c+g-w_{e} \cdot(e-k)\right] \cdot f(A)>1$, the joint optimal product pricing and emission ordering decisions are uniquely determined by the functions of $r^{m *}$ that satisfy $\left[\bar{p}^{m}-\frac{\Gamma\left(r^{m}\right)}{2 b}-c+g-w_{b} \cdot(e-k)\right] \cdot\left[1-F\left(r^{m}\right)\right]=w_{o} \cdot(e-b)$. Additionally, the optimal 
total emission quantity and selling price are $q^{m *} \equiv q\left(p^{m *}\right)=(e-k) \cdot\left(y\left(p^{m *}\right)+r^{m *}\right), p^{m *} \equiv p\left(r^{m *}\right)=$ $\bar{p}^{m *}-\frac{\Gamma\left(r^{m *}\right)}{2 b}$, respectively.

Proof. Please see the Appendix A.

Proposition 4. Under the mixed emission ordering policy, the higher option and higher exercising price lead to a decline in the product pricing and emission quantity decisions.

$\frac{\partial r^{m *}}{\partial w_{o}}<0, \frac{\partial r^{m *}}{\partial w_{e}}<0 ; \frac{\partial p^{m *}}{\partial w_{o}}<0, \frac{\partial p^{m *}}{\partial w_{e}}<0 ; \frac{\partial m^{m *}}{\partial w_{o}}<0, \frac{\partial q^{m *}}{\partial w_{e}}<0$. The optimal solutions of $q^{m *}, p^{m *}$ and $r^{m *}$ are decreasing in $w_{0}$ and $w_{e}$. The higher option and exercising prices reduce the hedging effect of the call option contract; therefore, the manufacturer tends to lower the emission option quantity for a lower option cost and to reduce the selling price for fewer spare emission options.

Proof. Please see the Appendix A.

Proposition 5. The demand uncertainty lowers the optimal selling price of the product.

$\frac{\Gamma\left(r^{n}\right)}{2 b}, \frac{\Gamma\left(r^{0}\right)}{2 b}$, and $\frac{\Gamma\left(r^{m}\right)}{2 b}$ are non-negative; therefore, the optimal selling price is the riskless price less the price loss, and $p^{n *} \leq \bar{p}^{n}$, $p^{o *} \leq \bar{p}^{o}$, and $p^{m *} \leq \bar{p}^{m}$.

\section{Numerical Analysis}

This section describes a representative numerical study to analyse the impact of the three emission ordering policies on the manufacturer's profitability. Additionally, this section further illustrates how the option contracts affect the optimal decisions and the expected profit through the option and exercising price. Moreover, the changes in the carbon market are considered (e.g., the demand risk, carbon price, and emission cap level). Certain managerial insights are correspondingly provided for better performance by the manufacturer.

Chinese fertilizer industry has been a strong driver of energy use and emission generation, therefore, the fertilizer industry in China bears many social responsibilities and legal obligations to fulfill the emission reduction targets. Therefore, the phosphatic fertiliser industry supports the data collection used in this numerical analysis.

All data are from the Chinese phosphatic fertiliser industry and are shown, as follows. $a=400$ (100 ton) $, b=1, c=$ US $\$ 200, e=2, k=1, w_{b}=$ US $\$ 10, w_{0}=$ US $\$ 4, w_{e}=$ US $\$ 8$, $g=$ US $\$ 10, s=$ US $\$ 2, A=-40$, and $B=60$. These data mean that the linear riskless demand is built as $y(p)=400-p$ based on the work of Heady and Yeh [35]. A uniform distribution is adopted to simulate the demand risk varying within the range of $\varepsilon \in[-40,60]$, as we assume that the demand fluctuates between 10 15\% of the market scale [36], and the coefficient variation that reflects the demand risk is $C V=2.89$. The unit cost of the phosphatic fertiliser is US $\$ 200$ per ton, including the production, inventory, and managerial costs. The emission level of phosphatic fertiliser $(e=2)$ means that producing 1 ton of phosphatic fertiliser generates two tons of emissions. The level assumes the government caps the emissions $(k=1)$ at 1 ton of emissions per ton of phosphatic fertiliser. This level means that the additional 1 ton of emissions must be purchased from the emission permit supplier for each product ton at the US $\$ 10$ price. If the call option contract is allowed, then the option price is US $\$ 4$, and the exercising price is US $\$ 8$ per ton emission. When emission shortages occur, the manufacturer may bear unsatisfied orders or lose demand at the cost of US $\$ 10$ per ton product. The spare emission can be resold at US $\$ 2$ after the selling period. 


\subsection{Results from Three Ordering Policies}

\subsubsection{Results Comparison}

Based on the data settings, the optimal decisions and expected profits achieved in these three emission ordering policies are given in Table 3. Moreover, all of the units used in the following Figures are elaborated in Table 3.

Table 3. Optimal decisions and expected profits for three emission ordering policies.

\begin{tabular}{ccccc}
\hline & Unit & Mixed Model & Non-Option Model & Only-Option Model \\
\hline$r$ & 100 ton & 56.4276 & 53.2137 & 56.4592 \\
$p$ & USD & 309.9681 & 309.8849 & 310.9687 \\
$q$ & 100 ton & 146.4595 & 143.3289 & 145.4905 \\
$q_{o}$ & 100 ton & 63.0943 & 0 & 145.4905 \\
$q_{b}$ & 100 ton & 83.3652 & 143.3289 & 0 \\
profit & 100 USD & 9740.4772 & 9627.1319 & 9608.0806 \\
\hline
\end{tabular}

The manufacturer obtains the best performance in the mixed model, and it orders the largest emission quantity, including the emission orders and options, from the emission permit supplier. It is reasonable to purchase more emission options that exceed the stocking factors since the risk of lower demand exists. The non-option model makes the manufacturer stock the fewest emission quotas because of the high spare emission cost. To reduce the shortage risk, the lowest selling price is set for more customer demand. The profitability of the only option model performs the worst, as this model bears the highest emission cost. The resulting highest selling price reduces the end demand. However, the only option model allows for the manufacturer to set the highest stocking factor, under which the firm bears the lowest shortage risk.

\subsubsection{Influences of Demand Risk}

The optimal decisions and the profit values under a specific market have been studied, as described above. The behaviours and performance of the manufacturer under the different demand risks deserve further discussion, as shown in Figure 1. The mixed ordering policy retains its supremacy on the total emission quantity and expected profit, and the non-option emission ordering policy suffers more with the increasing demand uncertainty. The only option policy has more supply flexibility. However, the policy incurs greater purchasing cost due to $w_{o}+w_{e}>w_{b}$.
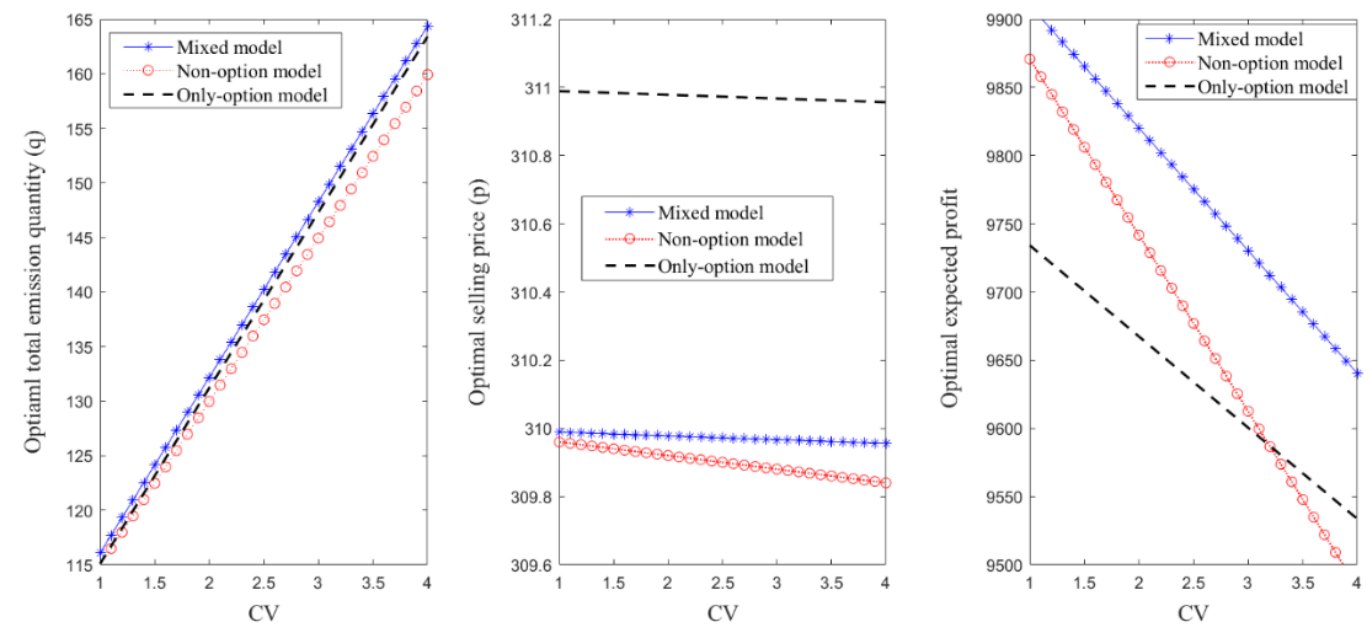

Figure 1. Optimal decisions and expected profits when demand risk varies. 
The optimal total emission quantities significantly increase, while the optimal expected profits experience a sharp decrease when the demand risk rises. The CV of the demand weakly influences the selling price through a slight decrease.

It is rational to order more emissions when the demand suffers more uncertainty. The manufacturer improves its supply flexibility through a larger emission quantity to address the more severe demand jump. The larger emission quantity raises the possibility of more spare emission costs, such that a lower selling price is charged to attract more customers. A trade-off exists between the emission cost and the supply flexibility.

Managerial Insight 1: The only option emission ordering policy has more supply flexibility but it behaves poorly in terms of profitability.

Although the mixed emission ordering policy performs better in terms of profitability, the only option policy is more capable of addressing the demand uncertainty. Relative to the non-option model, this policy earns more when the demand risk is high and less when the demand risk is low.

\subsubsection{Influences of Price Elasticities}

The behaviours and performance of the manufacturer under the different price elasticities deserve further discussion, as shown in Figure 2. The mixed ordering policy gains more profitability and requires more emission quantity compared to the others. The firm charges the highest selling price under the non-option emission ordering policy.

When the demand becomes more sensitive to the demand, the firm tends to reduce its selling price to attract more customers, and due to the decreasing demand from higher price elasticities, the profitability decreases, and less emission quantity is required.

Managerial Insight 2: The profitability of the mixed emission ordering policy outperforms the others.
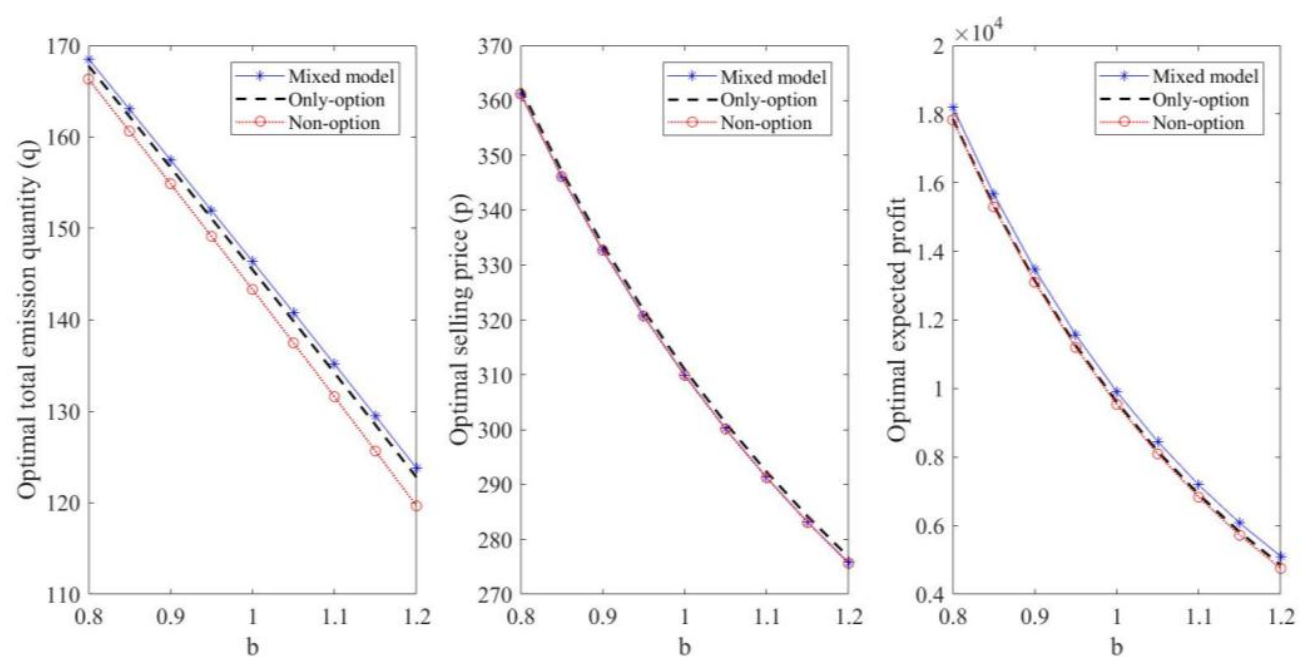

Figure 2. Optimal decisions and expected profits when price elasticity varies.

\subsection{Influences of Option Contracts and the Carbon Market}

\subsubsection{Influences of Option Contracts}

Figures 3 and 4 show that the mixed emission ordering policy performs better with an increasing option and exercising price, respectively. Apparently, the changes in the option contract are not rational to the profitability of the non-option model. The only option emission ordering policy is substantially influenced, and it becomes inferior to the non-option policy when the call option contract is overly expensive. The mixed policy is superior, although the option contract is costly. The worst profit result in the mixed model is to achieve the non-option level. The emission quantities of the mixed and 
only option models decrease in the increasing option cost, while the relationship between the optimal selling price and the option cost is intricate.

Managerial Insight 3: The mixed emission ordering policy is more capable of addressing price volatility.
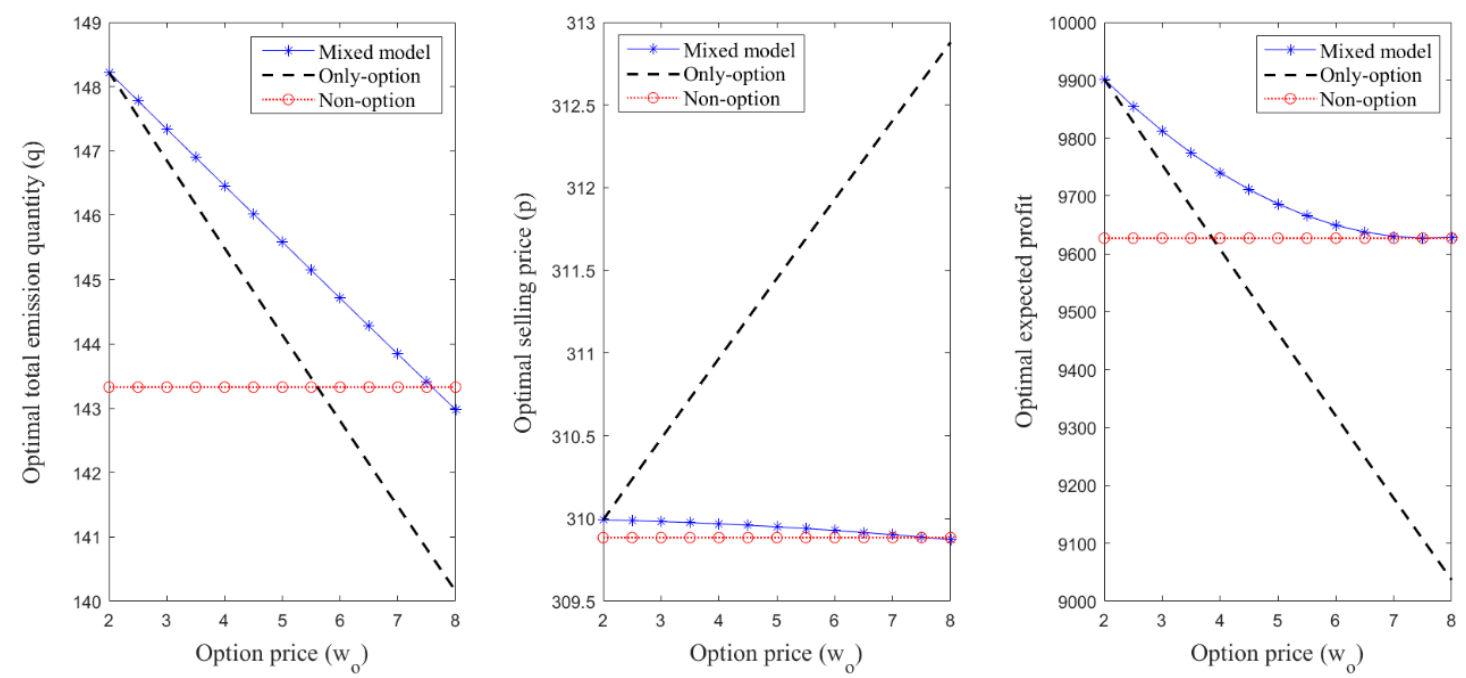

Figure 3. Optimal decisions and expected profits when option price varies.
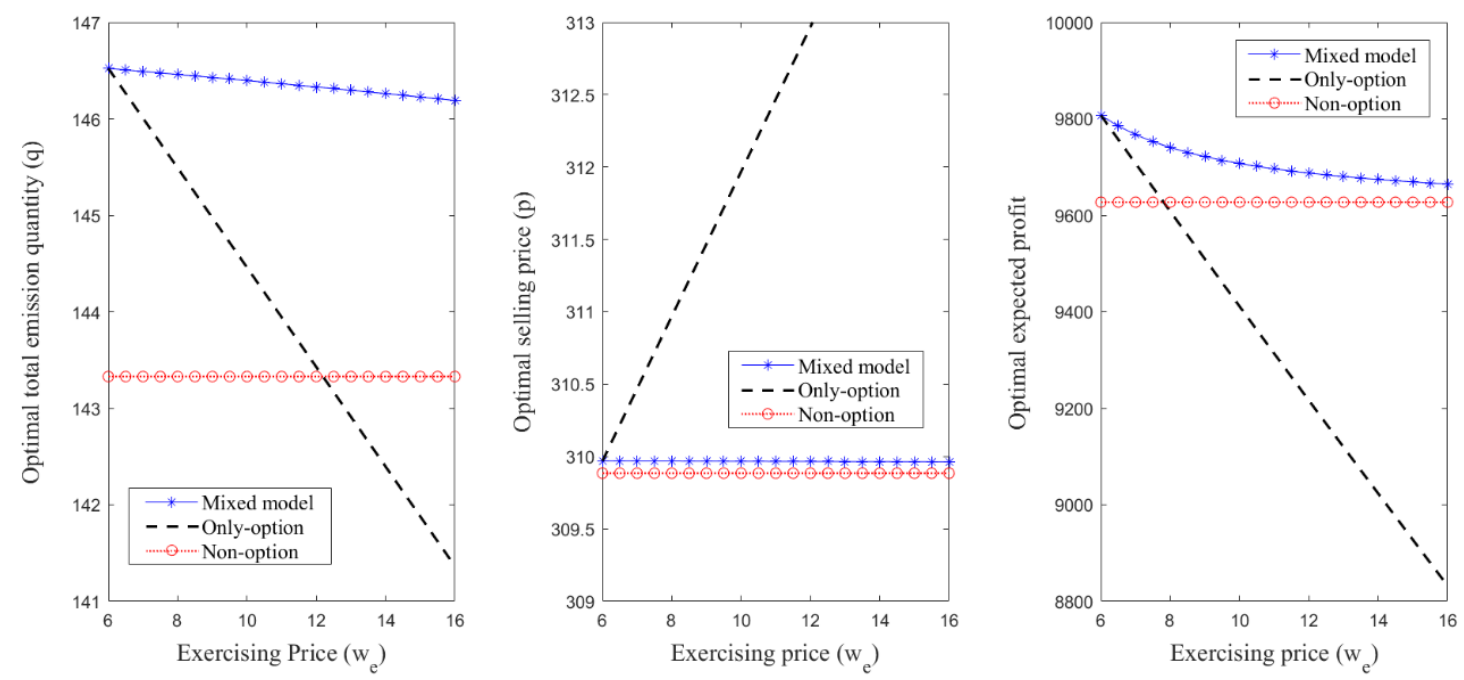

Figure 4. Optimal decisions and expected profits when exercising price varies.

\subsubsection{Influences of Carbon Market}

The influences of the emission cap level and the carbon price on the decision behaviours and the profit performance are discussed. According to Figure 5, the manufacturer obtains greater earnings due to the relaxation of the emission cap, since fewer emission quotas are required for production. The reduced emission cost reduces the selling price and the resulting demand increase is another reason for the expected profit growth. Clearly, the mixed emission ordering policy survives better in the stringent carbon market. 

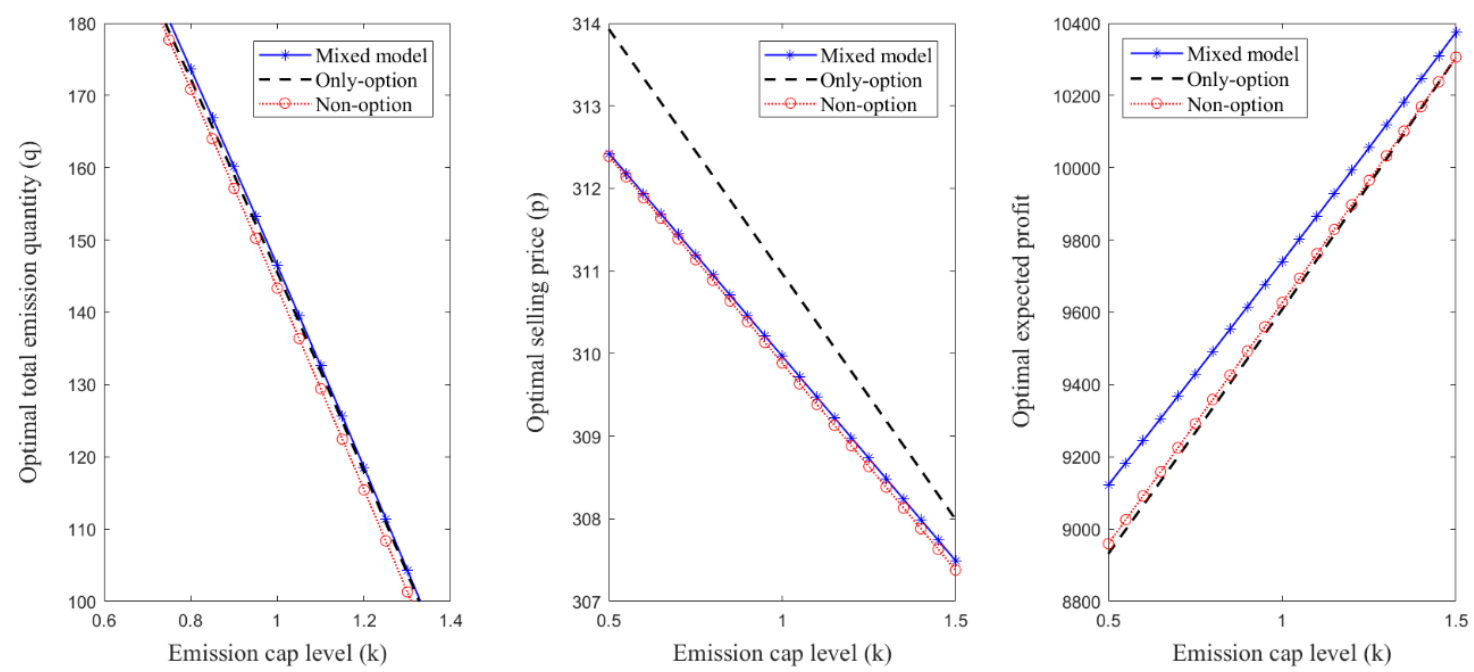

Figure 5. Optimal decisions and expected profits when cap level varies.

The option and exercising price are negotiated based on the carbon emission price. To analyse the impact of the carbon price, this paper simulated that these two prices were proportional to the carbon price, that is, $w_{o}=0.4 w_{b}$ and $w_{e}=0.8 w_{b}$. According to Figure 6 , the expected profit undergoes a sharp decline due to the synergistic impact of a lower emission quantity and a higher selling price. It is burdensome for the manufacturer to meet the low-carbon targets when the carbon price is high; however, the mixed emission ordering policy relieves this financial pressure by balancing the emission cost and the supplier flexibility.

Managerial Insight 4: Low carbon is costly, while the mixed emission ordering policy enables the manufacturer to better survive in the stringent carbon market.
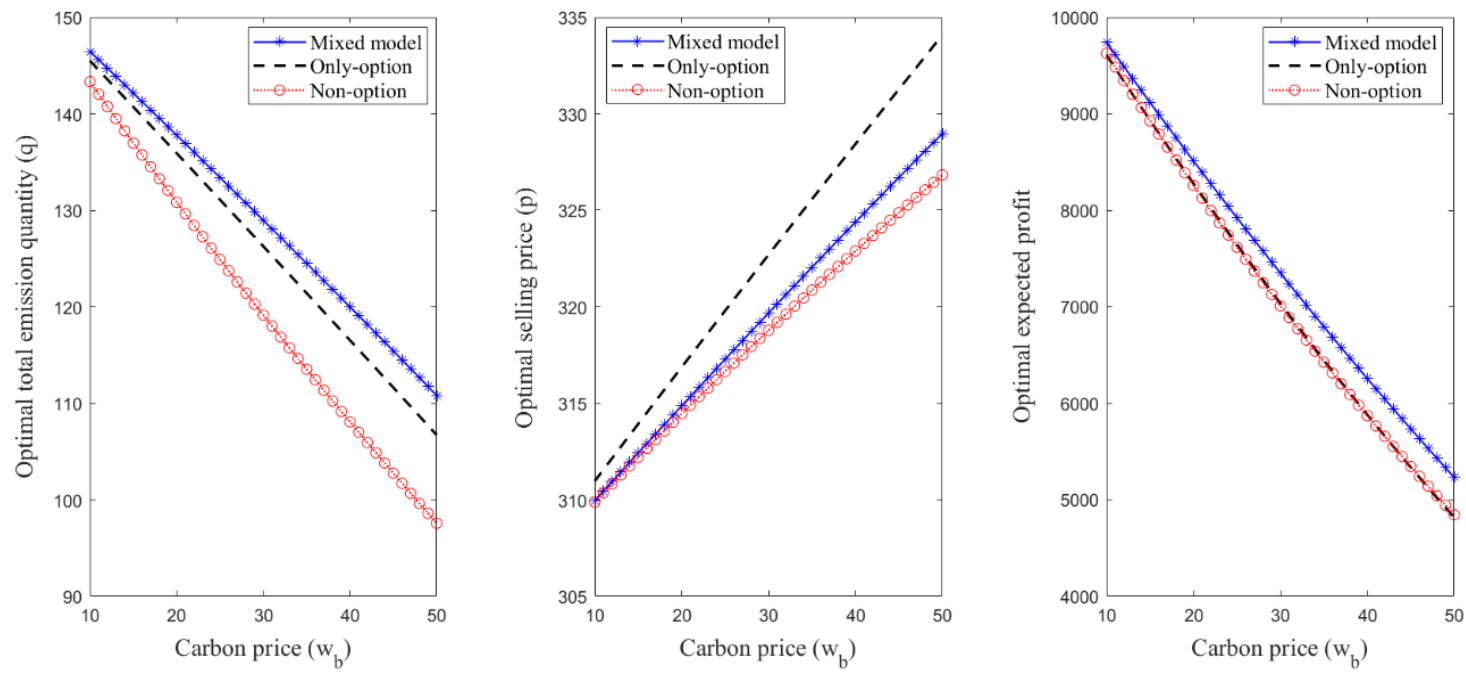

Figure 6. Optimal decisions and expected profits when carbon price varies.

\subsubsection{Emission Ordering Decisions in a Mixed Model}

As the mixed emission ordering policy was proven to outperform the others, it is worthwhile to explore the quantity decisions in terms of emission order and option quantities with different option contracts in different markets. Figure 7 shows that the emission order and the option quantities increase with the demand risk. Clearly, the higher option cost forces a reduction in the option quantity, and the emission order quantity correspondingly increases. Furthermore, the emission cap relaxation 
requires fewer emission permits per unit product; therefore, both quantities decrease with the loose emission cap.

Managerial Insight 5: The manufacturer sets larger emission orders when encountering a higher demand risk or option cost and lower orders when encountering loose low-carbon restrictions.

Managerial Insight 6: More emission options are required against higher demand uncertainty, and fewer options are required when encountering a higher option cost or loose low-carbon restrictions.
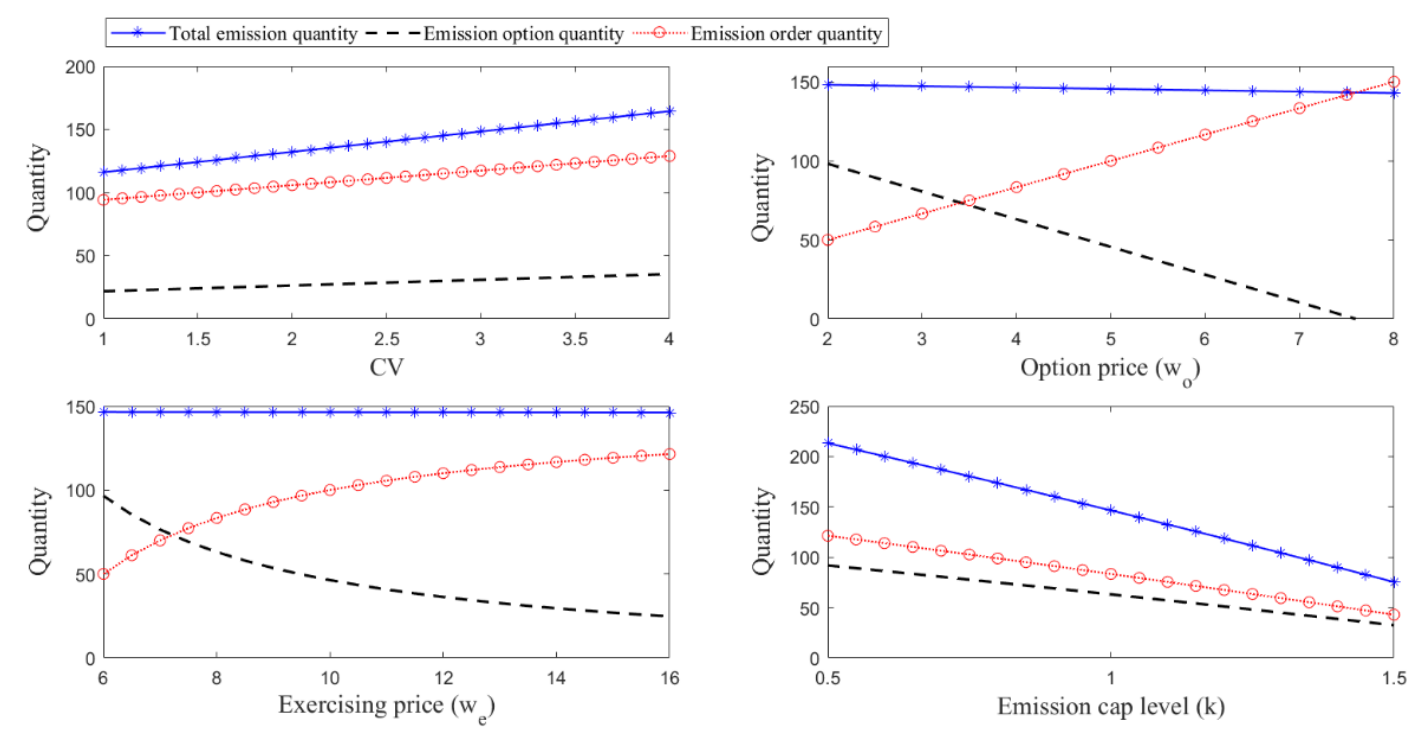

Figure 7. The quantity decision behaviours in the mixed model.

\section{Conclusions}

This study is the first to investigate the effects of using option contracts on emission-dependent manufacturers' behaviours and performances when emissions are limited by a flexible-cap ETS system. The introduction of the flexible emission cap provides more choices and patterns for the enterprise's carbon asset management. Therefore, three ordering policies were studied to improve the profitability and flexibility when facing uncertain demand, namely, mixed, only option, and non-option emission ordering policies.

The existence and uniqueness of the optimal decisions on the product pricing and emission ordering were mathematically proven. Numerical analysis further validated that the mixed emission ordering policy outperforms the others in terms of profitability and that the only option policy has more flexibility but exhibits poor profitability. Furthermore, the mixed ordering policy is more capable of addressing price volatility, and it enables the manufacturer to better survive in the stringent carbon market. Thus, the mixed emission ordering policy is the optimal solution when these three policies are available. Larger emission orders are determined against the higher demand risk or option cost, and fewer emission permits are required when the low-carbon restriction is loose. The options effectively hedge the demand uncertainty; therefore, it is reasonable to purchase more options when facing a higher demand risk. Furthermore, the higher option cost or the loose emission restrictions reduce the emission options. Under a mixed emission ordering policy, the higher option cost decreases the product selling price as well as the total emission quantity, and the manufacturer tends to charge a lower selling price against the higher demand risk.

These conclusions and managerial insights provide new approaches for emission-dependent manufacturers that are seeking to manage their carbon assets. The flexibility provided by options makes the manufacturer benefits more under higher demand risk, even in the stringent emission-limited market. A lower selling price is better for the manufacturer to hedge higher demand risk. Besides, the reasonable emission and option pricing is vital for the regulatory body to implement its low-carbon policy. 
Moreover, this research enables manufacturers to better survive in an increasingly stringent emission environment. Three directions exist for future research. First, a multi-period newsvendor can be considered; second, other financial derivatives can be used to optimise the decision behaviours and the performances of the manufacturers. Third, option-enabled supply chain coordination with different market structures warrants further discussion.

Author Contributions: S.W.: Formal analysis, Methodology, Writing-original draft; Z.W.: Data curation, Resources, Writing-review\&editing; B.Y.: Supervision.

Funding: This research received no external funding.

Conflicts of Interest: The authors declare no conflict of interest.

\section{Appendix A}

Proof of Proposition 1. When Hessian matrix is negative, the profit function is concave. Thus, there exists the local maximum point between $[A, B]$.

$$
\text { Hessian }=\left(\begin{array}{ll}
\frac{\partial^{2} E\left[\Pi\left(r^{n}, p^{n}\right)\right]}{\partial p^{n 2}} & \frac{\partial^{2} E\left[\Pi\left(r^{n}, p^{n}\right)\right]}{\partial p^{n} \partial r^{n}} \\
\frac{\partial^{2} E\left[\Pi\left(r^{n}, p^{n}\right)\right]}{\partial r^{n} \partial p^{n}} & \frac{\partial^{2} E\left[\Pi\left(r^{n}, p^{n}\right)\right]}{\partial r^{n 2}}
\end{array}\right)
$$

Ensuring the negative Hessian requires

$$
\text { Hessian }=2 b \cdot\left[p^{n}-c+g-s \cdot(e-k)\right] \cdot f\left(r^{n}\right)-\left[1-F\left(r^{n}\right)\right]^{2}>0
$$

By transformation, we get the following in equation:

$$
2 b \cdot\left[p^{n}-c+g-s \cdot(e-k)\right]>\frac{\left[1-F\left(r^{n}\right)\right]^{2}}{f\left(r^{n}\right)}
$$

Let $G\left(r^{n}\right)=\frac{\left[1-F\left(r^{n}\right)\right]^{2}}{f\left(r^{n}\right)}$, we can get the first condition of $G\left(r^{n}\right)$ as:

$$
G \prime\left(r^{n}\right)=\frac{-f \prime\left(r^{n}\right) \cdot\left[1-F\left(r^{n}\right)\right]^{2}-2\left[f\left(r^{n}\right)\right]^{2} \cdot\left[1-F\left(r^{n}\right)\right]}{\left[f\left(r^{n}\right)\right]^{2}}
$$

Suppose the demand distribution is NDFR, $G\left(r^{n}\right)$ is monotonically decreasing.

Since $\gamma^{\prime}(x)=\frac{f^{\prime}(x) \cdot[1-F(x)]+[f(x)]^{2}}{[1-F(x)]^{2}} \geq 0$, it is clear that

$$
-f^{\prime}\left(r^{n}\right) \cdot\left[1-F\left(r^{n}\right)\right]-2\left[f\left(r^{n}\right)\right]^{2} \leq-f \prime\left(r^{n}\right) \cdot\left[1-F\left(r^{n}\right)\right]-\left[f\left(r^{n}\right)\right]^{2} \leq 0
$$

Thus, we know $G \prime\left(r^{n}\right) \leq 0$ and $G\left(r^{n}\right)$ is monotonically decreasing. So that $G(x) \leq G(A)=\frac{1}{f(A)}$. When $2 b \cdot\left[p^{n}-c+g-w_{e} \cdot(e-k)\right] \cdot f(A)>1$ is satisfied, Hessian $>0$ is established. In this case, there exist the optimal ordering and price decisions by solving $\frac{\partial E\left[\Pi\left(r^{n}, p^{n}\right)\right]}{\partial p^{n}}=0$ and $\frac{\partial E\left[\Pi\left(r^{n}, p^{n}\right)\right]}{\partial r^{n}}=0$, respectively.

Let $\bar{p}^{n}=\frac{a+\left[c+w_{b} \cdot(e-k)\right] \cdot b+u}{2 b}$, we can have $\frac{\partial E\left[\Pi\left(r^{n}, p^{n}\right)\right]}{\partial p^{n}}=-2 b p^{n}+2 b \bar{p}^{n}-\Gamma\left(r^{n}\right)$. Thus $p^{n *} \equiv$ $p\left(r^{n}\right)=\bar{p}^{n}-\frac{\Gamma\left(r^{n}\right)}{2 b}$.

Substituting $p^{n *}=p\left(r^{n}\right)$ into the profit function $E\left[\Pi\left(r^{n}, p^{n}\right)\right]$, we can have

$$
\frac{\partial E\left[\Pi\left(r^{n}, p\left(r^{n}\right)\right)\right]}{\partial r^{n}}=-\left(w_{b}-s\right) \cdot(e-k)+\left[\bar{p}^{n}-\frac{\Gamma\left(r^{n}\right)}{2 b}-c+g-s \cdot(e-k)\right] \cdot\left[1-F\left(r^{n}\right)\right]
$$


The optimal value of $r^{n}$ can be given by $\frac{\partial E\left[\Pi\left(r^{n}, p\left(r^{n}\right)\right)\right]}{\partial r^{n}}=0$, that is,

$$
\left[\bar{p}^{n}-\frac{\Gamma\left(r^{n}\right)}{2 b}-c+g-s \cdot(e-k)\right] \cdot\left[1-F\left(r^{n}\right)\right]=\left(w_{b}-s\right) \cdot(e-k)
$$

Proof of Proposition 2. When Hessian matrix is negative, the profit function is concave. Thus, there exists the local maximum point between $[A, B]$.

$$
\text { Hessian }=\left(\begin{array}{ll}
\frac{\partial^{2} E\left[\Pi\left(r^{o}, p^{o}\right)\right]}{\partial p^{02}} & \frac{\partial^{2} E\left[\Pi\left(r^{o}, p^{o}\right)\right]}{\partial p^{o} \partial r^{o}} \\
\frac{\partial^{2} E\left[\Pi\left(r^{o}, p^{o}\right)\right]}{\partial r^{o} \partial p^{o}} & \frac{\partial^{2} E\left[\Pi\left(r^{o}, p^{o}\right)\right]}{\partial r^{02}}
\end{array}\right)
$$

Ensuring the negative Hessian requires

$$
\text { Hessian }=2 b \cdot\left[p^{o}-c+g-w_{e} \cdot(e-k)\right] \cdot f\left(r^{o}\right)-\left[1-F\left(r^{o}\right)\right]^{2}>0
$$

Like the proof of Proposition 1, we know that when $2 b \cdot\left[p^{0}-c+g-w_{e} \cdot(e-k)\right] \cdot f(A)>1$ is satisfied, Hessian $>0$ is established. In this case, there exist the optimal ordering and price decisions by solving $\frac{\partial E\left[\Pi\left(r^{0}, p^{0}\right)\right]}{\partial p^{0}}=0$ and $\frac{\partial E\left[\Pi\left(r^{0}, p^{o}\right)\right]}{\partial r^{0}}=0$, respectively.

Substituting $p^{o *}=p\left(r^{o}\right)$ into the profit function $E\left[\Pi\left(r^{o}, p^{o}\right)\right]$, we obtain the optimal value of $r^{o}$ by $\frac{\partial E\left[\Pi\left(r^{0}, p\left(r^{o}\right)\right)\right]}{\partial r^{o}}=0$, that is,

$$
\left[\bar{p}^{o}-\frac{\Gamma\left(r^{o}\right)}{2 b}-c+g-w_{e} \cdot(e-k)\right] \cdot\left[1-F\left(r^{o}\right)\right]=w_{o} \cdot(e-k)
$$

Proof of Lemma 6. Because

$$
\begin{aligned}
& \left\{\begin{array}{l}
\frac{\partial^{2} E\left[\Pi\left(\hat{q}_{o}^{m}, r^{m}, p^{m}\right)\right]}{\partial_{m}^{m 2}}=-\left(w_{e}-s\right) \cdot(e-k) \cdot f\left(r-\hat{q}_{o}^{m}\right)<0 \\
\frac{\partial^{2} E\left[\Pi\left(\hat{q}_{o}^{m}, r^{m}, p^{m}\right)\right]}{\partial r^{m 2}}=-\left[p^{m}-c+g-w_{e} \cdot(e-k)\right] \cdot f\left(r^{m}\right)-\left(w_{e}-s\right) \cdot(e-k) \cdot f\left(r^{m}-\hat{q}_{o}^{m}\right)<0
\end{array}\right. \\
& \text { Hessian }=\left(\begin{array}{ll}
\frac{\partial^{2} E\left[\Pi\left(\hat{q}_{o}^{m}, r^{m}, p^{m}\right)\right]}{\partial q_{o}^{m}} & \frac{\partial^{2} E\left[\Pi\left(\hat{q}_{o}^{m}, r^{m}, p^{m}\right)\right]}{\partial q_{0}^{m} r^{m}} \\
\frac{\partial^{2} E\left[\Pi\left(\hat{q}_{o}^{m}, r^{m}, p^{m}\right)\right]}{\partial r \partial_{0}^{m}} & \frac{\partial^{2} E\left[\Pi\left(\hat{q}_{o}^{m}, r^{m}, p^{m}\right)\right]}{\partial r^{m 2}}
\end{array}\right) \\
& =\left(w_{e}-s\right) \cdot(e-k) \cdot\left[p^{m}-c+g-w_{e} \cdot(e-k)\right] \cdot f\left(r^{m}\right) \cdot f\left(r-\hat{q}_{o}^{m}\right)>0
\end{aligned}
$$

Thus, Hessian Matrix is negative, and there exists the local maximum point for the profit function by solving $\frac{\partial E\left[\Pi\left(\hat{q}_{0}^{m}, r^{m}, p^{m}\right)\right]}{\partial \hat{q}_{0}^{m}}=0$ and $\frac{\partial E\left[\Pi\left(\hat{q}_{0}^{m}, r^{m}, p^{m}\right)\right]}{\partial r^{m}}=0$, respectively.

Proof of Proposition 3. When Hessian matrix is negative, the profit function is concave. Thus, there exists the local maximum point between $[A, B]$.

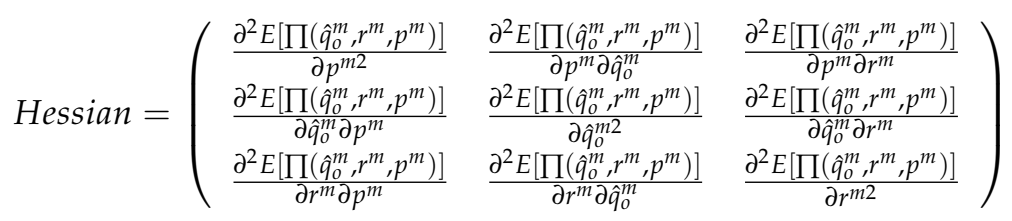

Ensuring the negative Hessian requires

$$
\text { Hessian }=\left[\begin{array}{l}
-2 b \cdot\left[p^{m}-c+g-w_{e} \cdot(e-k)\right] \cdot f\left(r^{m}\right) \\
+\left[1-F\left(r^{m}\right)\right]^{2}
\end{array}\right] \cdot\left(w_{e}-s\right) \cdot(e-k) \cdot f\left(r^{m}-\hat{q}_{o}\right)<0
$$


By transformation, we get the following in equation:

$$
2 b \cdot\left[p^{m}-c+g-w_{e} \cdot(e-k)\right]>\frac{\left[1-F\left(r^{m}\right)\right]^{2}}{f\left(r^{m}\right)}
$$

Like the proof of Proposition 1, we know that when $2 b \cdot\left[p^{m}-c+g-w_{e} \cdot(e-k)\right] \cdot f(A)>1$ is satisfied, Hessian $<0$ is established. In this case, there exist the optimal ordering and price decisions

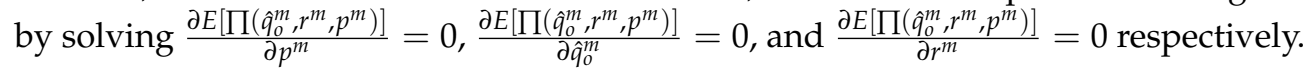

Let $\bar{p}^{m}=\frac{a+\left[c+w_{b} \cdot(e-k)\right] \cdot b+u}{2 b}$, we can have $\frac{\partial E\left[\Pi\left(\hat{q}_{o}^{m}, r^{m}, p^{m}\right)\right]}{\partial p^{m}}=-2 b p^{m}+2 b \bar{p}^{m}-\Gamma\left(\hat{q}_{o}^{m}, r^{m}\right)$. Thus $p^{m *} \equiv$ $p\left(r^{m}\right)=\bar{p}^{m}-\frac{\Gamma\left(r^{m}\right)}{2 b}$.

Substituting $p^{m *}=p\left(r^{m}\right)$ into the profit function $E\left[\Pi\left(\hat{q}_{o}^{m}, r^{m}, p^{m}\right)\right]$, we can have

$$
\left\{\begin{aligned}
\frac{\partial E\left[\Pi\left(\hat{q}_{o}^{m}, r^{m}, p^{m}\right)\right]}{\partial \hat{q}_{o}^{m},}= & -\left(w_{o}-w_{b}+w_{e}\right) \cdot(e-k)+\left(w_{e}-s\right) \cdot(e-k) \cdot F\left(r^{m}-\hat{q}_{o}^{m}\right) \\
\frac{\partial E\left[\Pi\left(\hat{q}_{o}^{m}, r^{m}, p^{m}\right)\right]}{\partial r^{m}}= & {\left[\bar{p}^{m}-\frac{\Gamma\left(r^{m}\right)}{2 b}-c+g-w_{e} \cdot(e-k)\right] \cdot\left[1-F\left(r^{m}\right)\right] } \\
& -\left(w_{e}-s\right) \cdot(e-k) \cdot F\left(r^{m}-\hat{q}_{o}^{m}\right)-\left(w_{b}-w_{e}\right) \cdot(e-k)
\end{aligned}\right.
$$

From $\frac{\partial E\left[\Pi\left(\hat{q}_{o}^{m}, r^{m}, p^{m}\right)\right]}{\partial \hat{q}_{0}^{m}}=0$, we get $F\left(r^{m}-\hat{q}_{o}^{m}\right)=\frac{\left(w_{0}-w_{b}+w_{e}\right)}{\left(w_{e}-s\right)}$, by substituting it into $\frac{\partial E\left[\Pi\left(\hat{q}_{0}^{m}, r^{m}, p^{m}\right)\right]}{\partial r^{m}}=0$, we can have

$$
\left[\bar{p}^{m}-\frac{\Gamma\left(r^{m}\right)}{2 b}-c+g-w_{b} \cdot(e-k)\right] \cdot\left[1-F\left(r^{m}\right)\right]=w_{o} \cdot(e-k)
$$

Proof of Proposition 4. Recall proof for Proposition 1, let $Z\left(r^{m}\right)=\frac{\partial E\left[\Pi\left(\hat{q}_{0}^{m}, r^{m}, p\left(r^{m}\right)\right)\right]}{\partial r^{m}}$, we know that $\frac{\partial \mathrm{Z}\left(r^{m *}\right)}{\partial w_{0}}=-(e-k)<0$. Since $\mathrm{Z}(B)=-w_{0} \cdot(e-k)$ and $r^{m *}$ is the maximum point that satisfies $\mathrm{Z}\left(r^{m}\right)=0$, we know that $\frac{\partial \mathrm{Z}\left(r^{m *}\right)}{\partial r^{m *}}<0$. According to the implicit function rule, it is clear that $\frac{\partial r^{m *}}{\partial w_{o}}=-\frac{\partial Z\left(r^{m *}\right)}{\partial w_{o}} / \frac{\partial Z\left(r^{m *}\right)}{\partial r^{m *}}<0$. Similarly, we can know $\frac{\partial r^{m *}}{\partial w_{e}}<0$.

From $\frac{\partial p^{m *}}{\partial r^{m *}}=\frac{1-F\left(r^{m *}\right)}{2 b}>0$ and $\frac{\partial r^{m *}}{\partial w_{o}}<0$, we can know $\frac{\partial p^{m *}}{\partial w_{o}}=\frac{\partial p^{m *}}{\partial r^{m *}} \cdot \frac{\partial r^{m *}}{\partial w_{o}}<0$. Similarly, we have $\frac{\partial p^{m *}}{\partial w_{e}}<0$.

From $\frac{\partial q^{m *}}{\partial p^{m *}}=-b<0, \frac{\partial p^{m *}}{\partial r^{m *}}<0$, and $\frac{\partial r^{m *}}{\partial w_{o}}<0$, we have $\frac{\partial \partial^{m *}}{\partial w_{o}}=\frac{\partial q^{m *}}{\partial p^{m *}} \cdot \frac{\partial p^{m *}}{\partial r^{m *}} \cdot \frac{\partial r^{m *}}{\partial w_{o}}<0$. Similarly, we have $\frac{\partial q^{m *}}{\partial w_{e}}<0$.

\section{References}

1. Pan, X.; Teng, F.; Wang, G. Sharing emission space at an equitable basis: Allocation scheme based on the equal cumulative emission per capita principle. Appl. Energy 2013. [CrossRef]

2. Zhou, P.; Wang, M. Carbon dioxide emissions allocation: A review. Ecol. Econ. 2016, 125, 47-59. [CrossRef]

3. Ellerman, A.D.; Buchner, B.K. The European Union emissions trading scheme: Origins, allocation, and early results. Rev. Environ. Econ. Policy 2007, 1, 66-87. [CrossRef]

4. European Commission. The EU Emissions Trading System (EU ETS); European Commission: Brussels, Belgium, 2017.

5. Chevallier, J.; Le Pen, Y.; Sévi, B. Options introduction and volatility in the EU ETS. Resour. Energy Econ. 2011, 33, 855-880. [CrossRef]

6. Cong, R.; Lo, A.Y. Emission trading and carbon market performance in Shenzhen, China. Appl. Energy 2017, 193, 414-425. [CrossRef]

7. Burton, E.S.; Sanjour, W. A simulation approach to air pollution abatement program planning. Socio-Econ. Plan. Sci. 1970, 4, 147-159. [CrossRef]

8. McAllister, L.K. Cap and trade. In Global Climate Change and US Law, 2nd ed.; American Bar Association: Chicago, IL, USA, 2014; pp. 341-373. 
9. Hu, H.; Zhou, W. A Decision Support System for Joint Emission Reduction Investment and Pricing Decisions with Carbon Emission Trade. Int. J. Multimedia Ubiquitous Eng. 2014, 9, 371-380. [CrossRef]

10. Du, S.; Ma, F.; Fu, Z.; Zhu, L.; Zhang, J. Game-theoretic analysis for an emission- dependent supply chain in a 'cap-and-trade' system. Ann. Oper. Res. 2015, 228, 135-149. [CrossRef]

11. García-Alvarado, M.; Paquet, M.; Chaabane, A.; Amodeo, L. Inventory management under joint product recovery and cap-and-trade constraints. J. Clean. Prod. 2016. [CrossRef]

12. Sabzevar, N.; Enns, S.T.; Bergerson, J.; Kettunen, J. Modeling competitive firms' performance under price-sensitive demand and cap-and-trade emissions constraints. Int. J. Prod. Econ. 2017, 184, 193-209. [CrossRef]

13. Xu, X.; Zhang, W.; He, P.; Xu, X. Production and pricing problems in make-to-order supply chain with cap-and-trade regulation. Omega 2017, 66, 248-257. [CrossRef]

14. Xu, X.; He, P.; Xu, H.; Zhang, Q. Supply chain coordination with green technology under cap-and-trade regulation. Int. J. Prod. Econ. 2017, 183, 433-442. [CrossRef]

15. Barnes-Schuster, D.; Bassok, Y.; Anupindi, R. Coordination and flexibility in supply contracts with options. Manuf. Serv. Oper. Manag. 2002, 4, 171-207. [CrossRef]

16. Gupta, A.; Maranas, C.D. Market-based pollution abatement strategies: Risk management using emission option contracts. Ind. Eng. Chem. Res. 2003, 42, 802-810. [CrossRef]

17. Wang, X.; Li, F.; Liang, L.; Huang, Z.; Ashley, A. Pre-purchasing with option contract and coordination in a relief supply chain. Int. J. Prod. Econ. 2015, 167, 170-176. [CrossRef]

18. Wan, N.; Chen, X. Multiperiodic Procurement Problem with Option Contracts under Inflation. Math. Probl. Eng. 2016, 2016. [CrossRef]

19. Wang, C.; Chen, X. Optimal ordering policy for a price-setting newsvendor with option contracts under demand uncertainty. Int. J. Prod. Res. 2015, 1-15. [CrossRef]

20. Wang, C.; Chen, X. Option pricing and coordination in the fresh produce supply chain with portfolio contracts. Ann. Oper. Res. 2017, 248, 471-491. [CrossRef]

21. Uhrig-Homburg, M.; Wagner, M. Derivative instruments in the eu emissions trading scheme-An early market perspective. Energy Environ. 2008, 19, 635-655. [CrossRef]

22. Chevallier, J.; Ielpo, F.; Mercier, L. Risk aversion and institutional information disclosure on the European carbon market: A case-study of the 2006 compliance event. Energy Policy 2009, 37, 15-28. [CrossRef]

23. Chesney, M.; Taschini, L. The Endogenous Price Dynamics of Emission Allowances and an Application to $\mathrm{CO}_{2}$ Option Pricing. Appl. Math. Finance 2012, 19, 447-475. [CrossRef]

24. Petruzzi, N.C.; Dada, M. Pricing and the Newsvendor Problem: A Review with Extensions. Oper. Res. 1999, 47, 183-194. [CrossRef]

25. Agrawal, V.; Seshadri, S. Impact of uncertainty and risk aversion on price and order quantity in the newsvendor problem. Manuf. Serv. Oper. Manag. 2000, 2, 410-423. [CrossRef]

26. Yao, L.; Chen, Y.F.; Yan, H. The newsvendor problem with pricing: Extensions. Int. J. Manag. Sci. Eng. Manag. 2006, 1, 3-16. [CrossRef]

27. Wang, C.X.; Webster, S. The loss-averse newsvendor problem. Omega 2009, 37, 93-105. [CrossRef]

28. Abad, P. Determining optimal price and order size for a price setting newsvendor under cycle service level. Int. J. Prod. Econ. 2014, 158, 106-113. [CrossRef]

29. Tang, O.; Musa, S.N.; Li, J. Dynamic pricing in the newsvendor problem with yield risks. Int. J. Prod. Econ. 2012, 139, 127-134. [CrossRef]

30. Jadidi, O.; Jaber, M.Y.; Zolfaghari, S. Joint pricing and inventory problem with price dependent stochastic demand and price discounts. Comput. Ind. Eng. 2017, 114, 45-53. [CrossRef]

31. Hu, X.; Su, P. The newsvendor's joint procurement and pricing problem under price-sensitive stochastic demand and purchase price uncertainty. Omega 2017, 79, 81-90. [CrossRef]

32. Mills, E.S. Uncertainty and price theory. Q. J. Econ. 1959, 73, 116-130. [CrossRef]

33. Qi, X.; Bard, J.F.; Yu, G. Supply chain coordination with demand disruptions. Omega 2004, 32, 301-312. [CrossRef]

34. Chen, Y.; Ray, S.; Song, Y. Optimal pricing and inventory control policy in periodic-review systems with fixed ordering cost and lost sales. Nav. Res. Logist. 2006, 53, 117-136. [CrossRef] 
35. Heady, E.O.; Yeh, M.H. National and regional demand functions for fertilizer. J. Farm Econ. 1959, 41, $332-348$. [CrossRef]

36. Tsao, Y.-C.; Lee, P.-L.; Chen, C.-H.; Liao, Z.-W. Sustainable newsvendor models under trade credit. J. Clean. Prod. 2017, 141, 1478-1491. [CrossRef] 